\title{
Classroom: A Space of Pedagogical Interaction
}

\author{
Carmen Aparecida Cardoso Maia Camargo, Marcio Antonio Ferreira Camargo, \\ Márcio Ferreira de Carvalho, Clere Ventura Costa Oliveira \\ University of Estate of Minas Gerais, Academic Unit of Passos, Minas Gerais, Brazil \\ Email: kkcamargo@yahoo.com.br, mcamargo2004@yahoo.com.br, mar.carvalho@yahoo.com.br, clereventuracosta@gmail.com
}

How to cite this paper: Camargo, C.A.C.M., Camargo, M.A.F., de Carvalho M.F. and Oliveira, C.V.C. (2018) Classroom: A Space of Pedagogical Interaction. Open Access Library Journal, 5: e4958.

https://doi.org/10.4236/oalib.1104958

Received: October 6, 2018

Accepted: October 19, 2018

Published: October 22, 2018

Copyright $\odot 2018$ by authors and Open Access Library Inc.

This work is licensed under the Creative Commons Attribution International License (CC BY 4.0).

http://creativecommons.org/licenses/by/4.0/

\section{c) (i) Open Access}

\begin{abstract}
Classroom is a socially instituted space of pedagogical intervention. This article aims to analyze how the interdisciplinary dialogue between teachers, in the classroom and outside of the classroom, in order to approach theory and practice in the teaching knowledge. It is part of a research project developed in 2017 in a Community Course, in the city of Passos-MG, Brazil. Based on a qualitative approach, there was an exploratory and descriptive design involving semi-structured interviews with eight teachers. Content analysis was used to treat the data. From the data found, it was evident that the general recognition of the teachers about the necessity and importance of the adequacy of teaching methods in relation to the interdisciplinarity in the teaching routine makes it a tool of approximation between the student and the learning. On the other hand, the interviewees identified some difficulties in programming interdisciplinary practices, such as understanding the importance of dialogue with content in everyday practice and the excessive daily demands of teaching work that prevent the involvement of all educators. However, they are unanimous in emphasizing the need to create joint pedagogical strategies, seeking a more meaningful knowledge for the student.
\end{abstract}

\section{Subject Areas}

Education

\section{Keywords}

Interdisciplinarity, Pedagogical Practices, Interdisciplinary Planning

\section{Introduction}

Interdisciplinary practice is a subject that has been debated since the 1970s in Brazil by some scholars. However, now, with the National Higher Education Examination (ENEM) and more recently a proposal that is being processed by 
the National Education Council (CNE) aimed at joining.

In High School, the use of areas of knowledge (Humanities, Sciences of Nature, Languages, Codes and Mathematics), replacing the thirteen previous disciplines, it is evident that such a model needs more than ever to be debated, especially with regard to the posture and dedication of the teachers and with respect to the feasibility of the application of this model. Initially, it is necessary to analyze what has become interdisciplinarity, since the first debates in Brazil, reflecting on the epistemology of this concept and its application in the school environment. According to the National Curriculum Parameters (PCNs), "interdisciplinarity refers to an epistemological approach to the objects of knowledge" [1].

In schools, the compulsion of certain content has diverted teachers from the real needs of their students, who are often subjected to an overload of fragmented contents and activities. According to the National Curricular Parameters High School:

(...) interdisciplinarity must go beyond the mere juxtaposition of disciplines and, at the same time, avoid dilution of them in generalities. In fact, it will be mainly in the possibility of relating the disciplines in activities or projects of study, research and action that the interdisciplinarity could be a pedagogical and didactic practice adequate to the objectives of the High School [1].

Linked to the above conception, interdisciplinarity as a practice in the classroom is still far from the reality of school environments and the training of educators. In this way, it needs a greater understanding on the part of the educators in the theoretical part, as well as in the practical one.

According to the educator Ivani Fazenda [2], an interdisciplinary attitude is needed, which is nothing more than an attitude of search, inclusion, agreement and attunement to the knowledge where everyone wins: the students, because they learn to work in group, are accustomed to this group learning experience, and educators, because they are compelled to improve interaction with colleagues and to increase knowledge in other areas of knowledge.

In Brazil, in the mid-1970s, one of the first authors to reflect on the term interdisciplinarity emphasizes that interdisciplinarity or interdisciplinary space "should be sought in denying and overcoming disciplinary boundaries" [3]. More recent studies present interdisciplinarity as an awareness of the need for an explicit and direct interrelationship between all disciplines. In other words, "interdisciplinarity is the attempt to overcome a historical process of abstraction of knowledge that culminates in the total disarticulation of knowledge that our students (and us, teachers) have the displeasure to experience" [4].

The school has become, over the years, a space of isolated knowledge that does not interact with each other. In this case, such isolation, most of the time, is a consequence of the lack of a consistent interdisciplinary project. What can be perceived nowadays is that teaching-learning practices in schools are limited because: 
The piecemeal and compartmentalized, mechanistic, disjunctive, and reductionist intelligence breaks the complex of the world into disjointed fragments, breaks down the problems, separates what is united, makes it more difficult to grasp what is woven together. one-dimensional or multidimensional [5].

In this way, the interdisciplinary proposal is to establish links between knowledge, aiming to guarantee the construction of a globalizing knowledge, facing the complexity of reality, at the same time rescuing the centrality of man in reality and in the production of knowledge. "Interdisciplinarity is characterized by the intensity of exchanges between specialists and the degree of real integration of disciplines within the same research project" [3].

If, on the one hand, the interdisciplinary model instigates the disruption of fragmentation, on the other, it needs good planning for its effectiveness. Thus, the project must be interdisciplinary in its conception, execution, evaluation and the concepts used can be formalized and registered within the scope of the disciplines that contribute to its development [1]. As observed in Edgar Morin's statement, "the separation and accumulation of knowledge can no longer be privileged to the detriment of the organization linking knowledge" [5].

Therefore, interdisciplinary work involves attitude and method, involving content integration; from a fragmented perception to a unitary conception of knowledge. Articulate/relate knowledge, information, experiences, environment, school, community, has now become the goal of interdisciplinarity manifested by a collective and supportive doing in the school organization.

Thus, a new way of thinking is required, resulting in an exchange, reciprocity and integration between different areas of knowledge, aiming at the production of new knowledge, global and comprehensive problem solving, first of all, a change of attitude.

\section{Materials and Methods}

The present project had the objective of analyzing the perception about the practice of interdisciplinary dialogue among teachers, in the classroom and beyond. It made it possible to bring the subject up to the teachers and the possibility of constructing teaching-learning alternatives, in view of the challenges and possibilities of the new proposal for High School.

It is a field research, qualitative approach, exploratory and descriptive. Qualitative for being a study directed to the interpretation of meanings and quantitative by characterizing the group studied in relation to different variables According to Minayo [6], the qualitative method is:

What applies to the study of history, relationships, representations, beliefs, perceptions and opinions, the products of human beings' interpretations of how they live, build their artifacts and themselves, feel and think.

The research was carried out at the Dércio Andrade-Educafro Community 
Cursillo, in the city of Passos, Minas Gerais. The Cursinho project was born in front of the initiative of Pastoral do Negro, created in the city in 1995. Currently the Cursinho works with a class of 50 students. Its faculty has 12 teachers and two coordinators, all of whom are volunteers.

The study was carried out in the months of May to July of 2017, with eight teachers who were willing to participate in it. All signed the Informed Consent Term (TCLE).

The instrument used for data collection was the semi-structured interview, which included the following aspects: Interdisciplinarity concept and the role of the teacher; the pedagogical doing; teacher-student relationship in the Interdisciplinary Process; challenges of interdisciplinary work and planning and implementation of interdisciplinary work. The categorized data were analyzed through the technique of content analysis, which for Bardin (1979) is a set of communication analysis techniques aiming to obtain, through systematic and objective procedures, the description content of messages. To characterize the participants, a demographic questionnaire was used, with questions about sex, the discipline that ministered, time in teaching and the schooling of the interviewees.

\section{Results and Discussion}

Based on the interview data, all teachers have, besides graduation, a postgraduate degree in the related area and have one and ten years of experience in teaching, the vast majority of males. When questioned about the concept of interdisciplinarity, the answers varied with respect to the form of expression, but, in short, they generically produce the same response that concerns interdisciplinarity to be a constant dialogue between the knowledge, providing a look at teaching and practices in an integral and global way without separating or segregating both. As stated below:

It is a teaching methodology that is characterized by the combination of activities and studies, where common concepts are used between subjects and contents and thus, implies in the articulation of disciplinary actions that seek a common interest of the contents involved.

The purpose of the interdisciplinary question is to overcome the dichotomy between theory and practice, thus becoming a tool for approaching the student and learning, articulating the amplification of the vision of the same, making the teacher, according to the interviewees, as a mediator, or facilitator, according to the need in question.

Regarding the interdisciplinary pedagogical practice in daily practice, teachers affirmed that interdisciplinarity is a constant present in all areas of knowledge and that the teacher must know how to dialogue, seeking to broaden his vision in the preparation of classes. All were unanimous in affirming that they offer classes with an interdisciplinary focus, according to the reports: 
I try to make the interdisciplinarity with Portuguese Language, comparing it with Spanish, using the analogy between equalities and differences, aiming at a better memorization on the part of the students. With History, in the explanation of the history of the Spanish-speaking countries. With Mathematics, making analogy with the differences of nomenclature of the punctuation marks aiming at a better understanding and memorization. Art, valuing the predominant art in the Spanish-speaking countries.

As I have already mentioned, the Language for Music Project works the language through group work, in the classroom, presenting bands or singers of Brazilian music of the most varied musical genres. In this way it is possible to make an intersection with the history, contextualizing the work of the band or the singer, with the philosophy, thinking about the positioning and the reflections of the songs and many others.

Based on the reported observations, in relation to teaching within the interdisciplinary perspective, the answers confirm that it is possible to interact between seemingly distinct disciplines. This interaction is a complementary or supplementary way that enables the formulation of a critical-reflexive knowledge, which knowledge must be valued each time in the teaching-learning process.

Therefore, it is the teacher's role to "enchant" the student by his or her way of selecting, organizing, contextualizing the contents, thus promoting the student's intellectual development and helping him in his construction as a subject, that is, as a social being.

Regarding the perceptions regarding the teacher-student relationship in the interdisciplinary process, they reported that the relationship between both is a construction and is always in the process of changes, adaptations and exchanges of knowledge, in addition to the incentive to expand visions, the tendency is that this construction solidify and grow constantly. As you read below:

Curiosity on the part of the students is perceptible. Students can see that one discipline has a complete connection with another and thus becomes more interested in the different disciplines of knowledge.

The relationship between student and teacher is a construction. It is always in the process of evaluation (not of evaluation as evidence, but of perception of reality) in which both students and teacher self-evaluate. It is a construction that generates results, because in the course of the presentation of the discipline, the relationship is becoming stronger and teacher and students strengthen their work together. The student feels more confident in the teacher and asks for suggestions, interferes in the classes, participating in the construction of knowledge.

These reports corroborate the thinking of Paulo Freire, working with interdisciplinary projects, "both educators and students, involved in a research, will no 
longer be the same. The results should imply more quality of life, should be indicative of more citizenship, more participation in the decisions of daily life and social life. They must, finally, nourish the possible dream and utopia necessary for a new logic of life" [7].

Regarding the difficulties of introducing interdisciplinarity, teachers are unanimous in stating that time is the greatest of them, whether it is the difficulty for the encounter between teachers or the teacher's own time of availability on their professional life, also corroborate, the scarcity of interdisciplinary material; the absence of the habit of seeking new knowledge that comes mainly from the professionalism of the professional, the plastering of the menus, among others.

Despite the challenges presented, teachers see interdisciplinarity as a positive strategy in the teaching-learning process.

Regarding the planning and implementation of interdisciplinary work, in all the reports, the importance of breaking the barriers between teachers so that the interdisciplinary proposal materializes, both for the need of a more consistent and useful learning through the methods and the mutual motivation between teacher and student, when due to the evident need to adapt teaching to the new means of student admission.

Referring to the implementation of the interdisciplinary practice in High School and the Pre-Vestibular Cursillo, the teacher below reports categorically:

The world is interdisciplinary. The view that the human being has today is holistic. This happens mainly with the advent and evolution of the media, especially the internet. The search for contents and information of the most varied areas and thematic places the subject in a constant dialogue between areas. At school, be it regular or a community course, as is the case, is the appropriate place to systematize and direct this range of information present in the modern world. We can say that the student never arrives with a zero level of knowledge about any subject. Taking advantage of what the student brings with him/her and promoting, therefore, the movement of this knowledge in several areas is of paramount importance.

It is notorious that the interviewed teachers, more and more, have had to adapt to the new teaching tools, and these, in turn, have become more and more interdisciplinary, constantly charging for the change of teaching.

\section{Conclusions}

Based on the studies presented in the Theoretical Foundation, the understanding and analysis of the data collected on the results obtained become a reaffirmation of everything that has been consolidated on the subject of interdisciplinary pedagogical practices.

This research aimed to investigate, together with teachers, teaching-learning alternatives to the interdisciplinary field and to the reception of this new model in teaching practice, in the daily life, in view of the challenges and possibilities of the new proposal for High School, and for besides this focus, to seek a theoretical 
deepening in relation to the process of insertion of this interdisciplinary proposal and to reflect on possible supports for its effectiveness.

It is evident in the results obtained, the need pointed out by the teachers in the adoption of interdisciplinary practices in the teaching-learning process. This need is related to the interdisciplinary and not fragmented look.

In addition, it is unanimous among the interviewees, the constant attempt to adapt the teaching plan to the interdisciplinary view, and also the difficulties and the challenges encountered with regard to the subject matter are common, and these are the time and material to devote to create an interrelated learning to the areas of knowledge.

The results obtained evidenced that the interdisciplinarity is characterized by the intensity of the exchanges between specialists. It consists in the fact that it incorporates the results of various disciplines. Some interdisciplinary attitudes depend on the culture, on the communication of specialists, and that they transcend their own specialties, becoming aware of their own limits to receive the contributions of the other disciplines.

Thus, the proposal to adapt the teaching of the interdisciplinarity, towards an education based on reciprocity and collective work, to make it less individualistic and isolated in all senses, should be the result of the collective construction carried out by the team teacher. Nothing can replace it in the task of modifying, enriching and building new and more powerful instruments of action and interpretation of certain area of knowledge.

However, it is also a general assertion that the teachers researched, even with the limitations presented, apply, within the possibilities, the interdisciplinary teaching through mainly projects and systems of study differentiated, based on the internal questions between teachers and students, about meaningful learning.

There are many challenges to reach interdisciplinarity, among them we highlight: assume a theoretical-methodological paradigm that admits contradictions, ambiguities, coexist with uncertainties; construct a critical and reflective perspective.

Finally, we hope, with this article, to share and start some reflections on the search for understanding and pedagogical application of innovative and interdisciplinary pedagogical practices.

\section{Conflicts of Interest}

The authors declare no conflicts of interest regarding the publication of this paper.

\section{References}

[1] BRASIL. Ministério da Educação, Secretaria de Educação Média e Tecnológica. (1999) Parâmetros Curriculares Nacionais: Ensino Médio. Ministério da Educação, Brasília.

[2] Fazenda, I.C.A. (2012) Interdisciplinaridade: história, teoria e pesquisa. 18th 
Edition, Papirus, São Paulo.

[3] Japiassú, H. (1976) Interdisciplinaridade e Patologia do Saber. Imago, Rio de Janeiro.

[4] Alves, N. and Garcia, R.L. (Orgs.) (2008) O Sentido da Escola. 5th Edition, Ed Mauad, Rio de Janeiro.

[5] Morin, E. (2003) A cabeça bem-feita: Repensar a reforma, reformar o pensamento. 8th Edition, Bertrand Brasil, Rio de Janeiro.

[6] Minayo, M.C.S. (2007) O desafio do conhecimento: pesquisa qualitativa em saúde. 10th Edition, Hucitec, São Paulo.

[7] Freire, P. (2011) Pedagogia da autonomia: Saberes necessários à prática pedagógica. 43rd Edition, Paz e Terra, São Paulo. 